Working Paper No. 605, 2003

Privatization and Restructuring in Concentrated Markets

by Pehr-Johan Norbäck and Lars Persson

IUI, The Research Institute of Industrial Economics

P.O. Box 5501

SE-114 85 Stockholm

Sweden 


\title{
Privatization and Restructuring in
}

\author{
Concentrated Markets
}

\author{
Pehr-Johan Norbäck* \\ Research Institute of Industrial Economics
}

Lars Persson

Research Institute of Industrial Economics and CEPR

November 11, 2003

\begin{abstract}
This paper examines the restructuring of state assets in markets deregulated by privatizations and investment liberalizations. We show that the government has a stronger incentive to restructure than the buyer: A firm restructuring only takes into account how much its own profit will increase. The government internalizes that restructuring increases the sales price not only from the increase in the acquirer's profit, but also from a reduced profit for the non-acquirer, whose profits decrease due to its rival's restructuring. We also identify situations where a slow sale can significantly reduce the sales price because of strategic investment and product market effects.

Keywords: Privatization, Asset Ownership, Restructuring
\end{abstract}

JEL classification: D44, L1, L33, L4, P31

${ }^{*}$ We have benefited from useful comments from Peter Norman and Johan Stennek and participants in seminars at IUI in Stockholm and University College Dublin. Financial support from the Marianne and Marcus Wallenberg Foundation, and Tom Hedelius' and Jan Wallander's Research Foundations, is gratefully acknowledged. Email: larsp@iui.se. 


\section{Introduction}

In liberalization and privatization programs, we observe that governments use (or encourage) different types of restructuring prior to privatization (liberalization). Specific areas of restructuring include (1) a change in management and labor, (2) efficiency programs and (3) investment and de-investment programs. ${ }^{1}$ This presents a puzzle: Why would a government restructure state assets instead of leaving it for the buyer to decide? The private buyer should be able to achieve efficiency goals at the same cost and more in line with her specific needs.

In the literature, informational, political and financial restrictions have been suggested to explain why governments should (sequentially) restructure prior to privatization. (See for instance, Roland (1994)). In contrast, this paper takes as its starting point that many of these restructuring programs have been carried out in oligopolistic markets, including the manufacturing sector, utility and communication services as well as the financial sector. $^{2}$ In this paper we show that in an oligopoly, a government may have a stronger incentive to restructure than a buyer of the privatized firm. Emphasizing oligopolistic interaction, we thus provide an additional explanation of why governments restructure prior to privatizations.

1 This was the case in, for instance, the Mexican privatization program in the 1980s and 1990s, see (Lopez-de-Silanes 1997). Moreover, British Steel, prior to its privatization, cut employment by $40 \%$ without loosing sales, while British Airways experienced a similar reduction of employment, while increasing the number of flights, see Djankov and Pohl (1997).

${ }^{2}$ Many countries also announce substantial forthcoming privatizations. Planned privatizations suggest that privatization proceeds will remain strong through continued activitities in Europe and Asia. Examples of countries with large privatization plans are China, Japan, Portugal, Thailand and Turkey (OECD (2000)). 
In the model there is initially a market which has previously been served by a state enterprise, which possesses local productive assets. The government then liberalizes the market through a program with two distinct measures: (i) selling the state assets, and (ii) deregulating the market by abolishing investment restrictions. In stage 0 , the government may restructure the state assets and thereby improve the profitability of their use in the product market. In stage 1, the (restructured) state assets will be sold at an auction where two firms simultaneously post bids and the bidder with the highest bid obtains the state assets. In stage 2, the acquirer has the option of further restructuring the state assets. In stage 3 , the non-acquiring firm invests in capital in order to be able to produce in the product market. In stage 4, firms compete in oligopoly fashion generating profits.

We show that the government has a stronger incentive to restructure than a private buyer, since the government internalizes externalities on rival firms via the sales price of the privatized firm. A firm restructuring takes into account how much its own profit will increase from the process. The government, on the other hand, takes into account how the acquisition price is affected. The acquisition price is, in equilibrium, shown to be equal to a firm's valuation of obtaining the state assets. A firm's valuation, in turn, consists of the profit for this firm when obtaining the state assets, net of the profit for this firm when the rival firm obtains them. The government then internalizes that restructuring increases the sales price, not only from generating an increase in the acquirer's profit, but also through the negative impact on the non-acquirer's profit as an outcome of the restructuring.

There is, however, some recent evidence showing that restructuring policies can be very costly. Lopez-de-Silanes (1997) estimates that the direct cost of prior restructuring 
policies delaying the privatization process, amounted to an average of $33 \%$ of the sales price in Mexico. A slow sale of the assets may lead to lower productivity due to, for instance, managerial distraction, misconduct and lost investment opportunities. In a situation without oligopolistic interaction, the acquisition price would then decrease with the amount of waste. However, we show that in an oligopoly a slow sale of the state assets will have strategic investment and product market effects, that can lead to a substantially larger reduction of the sales price. We identify two different situations where a slow sale will reduce the sale price substantially as a result of strategic effects. The first, is when a slow sale implies that the acquirer will not have time to commit to sequential investments before the other firms make their investment decisions. The second, is when early entry provide the acquiring firm with a competitive advantage in the ensuing product market competition. For instance, an early entry could be crucial in creating consumer loyalty before rivals are present in the market. A slow sale will, in these situations reduce a firm's valuation of the state assets, and hence the sales price, for two reasons: (i) it reduces the acquiring firm's product market profit, and (ii) it increases the non-acquiring firm's product market profit.

To our knowledge, our paper is the first in the theoretical privatization literature or transition literature, to examine privatizations in a situation where potential buyers can invest in new capital and compete in an asymmetric oligopoly. ${ }^{3} 4$

\footnotetext{
${ }^{3}$ For overviews of the privatization literature see, for instance, Schmidt and Schnitzer (1997) and Vickers and Yarrow (1991).

${ }^{4}$ A related paper is Bennett and Maw (2002). However, the focus of their paper is to derive the welfare-maximizing retained ownership share for the state in a symmetric oligopoly, while we study restructuring incentives in an asymmetric oligopoly.
} 


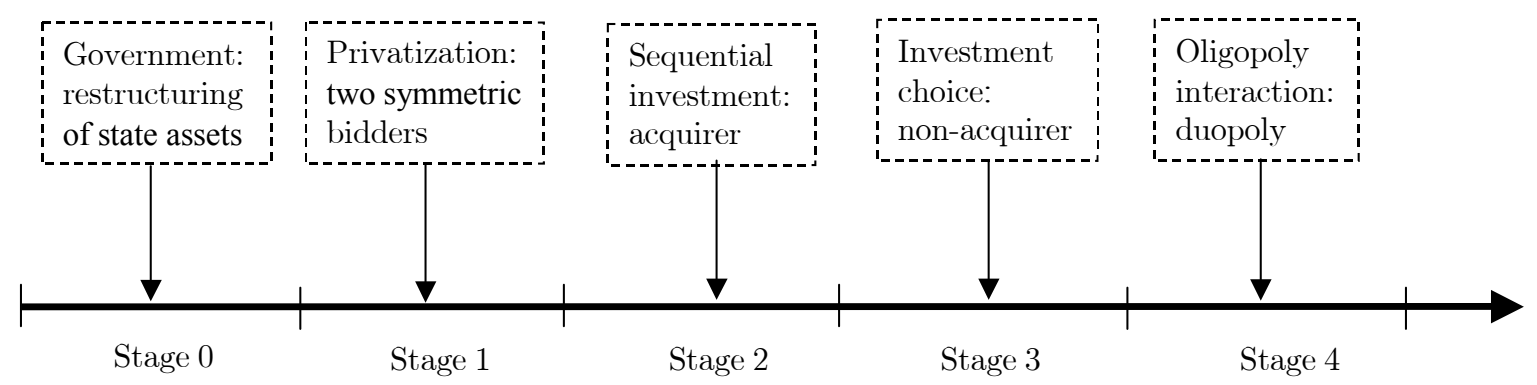

Figure 2.1: The structure of the game.

The model is spelt out in Section 2 and in Section 3, we derive the equilibrium restructuring and investment pattern and examine how government and private incentives may differ in restructuring. In Section 4, the effects of a delayed privatization are analyzed. Section 5 is the conclusion.

\section{The Model}

Let us start with a brief overview of the model. Consider a country where the market has previously been served by a state enterprise, which possesses $k_{0}$ units of productive assets. The government will liberalize the market through a program with two distinct measures: (i) selling the state assets, and (ii) deregulating the market by abolishing investment restrictions. The interaction takes place in five stages, as illustrated in Figure 2.1.

In stage 0 , the government may restructure the state-assets $k_{0}$ to $k_{G}$ and thereby improve the profitability of using the assets in the product market. In stage 1 , the state assets will be privatized. The privatization process is depicted as an auction ${ }^{5}$ where two

\footnotetext{
${ }^{5}$ In order to focus on the market forces as the determinants of the equilibrium market structure, we assume that the government sells the state assets to the highest bidder at an auction. Several western countries employ various kinds of auctions to sell state-owned enterprises to the
} 
firms simultaneously post bids, $b_{i}$, and the bidder with the highest bid obtains the state assets. $^{6}$ If more than one firm posts such a bid, each such firm obtains the assets with equal probability. The winning buyer pays an amount equal to his bid.

In stage 2 , the acquirer has the option of further restructuring state assets from $k_{G}$ to $k_{A}$ improving the profitability of using these assets even further. In stage 3 , the nonacquiring firm invest in capital $k_{N A}$ in order to be able to produce in the product market. Finally, in stage 4, firms compete in oligopoly fashion.

\section{Government and private incentives for restructuring}

To examine the incentives for restructuring faced by the government and a private firm, we shall solve the model for the equilibrium restructuring and investment pattern. As usual, we proceed by backward induction.

\subsection{Stage 4 : product market equilibrium}

We first describe optimal behavior in the product market interaction. Firm $i=\{A, N A\}$, where $A$ denotes the acquirer and $N A$ denotes the non-acquirer, chooses an action $x_{i} \in$ $R^{+}$to maximize its direct product market profit, $\Pi_{i}\left(x_{i}, x_{j}, k_{i}, k_{j}\right)$, which depends on its own and its rivals market actions, $x_{i}$ and $x_{j}$, as well as its own and the rival's capital investments, $k_{i}$ and $k_{j}$, undertaken prior to the market interaction. We may think of the highest bidder. In some transition countries, a substantial proportion of the shares of all firms was given to the general population free. Most privatization programs combined several elements of these basic methods. See Schmidt and Schnitzer (1997).

${ }^{6}$ All firms are completely informed about their own and other firms' characteristics. This allows us to clearly attribute market force effects, as opposed to, for instance, problems of incomplete information. 
action $x_{i}$ as setting a quantity or a price, as will be shown in later sections. We assume that there exists a unique Nash-Equilibrium in actions, $\mathbf{x}^{*}\left(k_{i}, k_{j}\right)$, defined from the first-order condition (3.1):

$$
\frac{\partial \Pi_{i}}{\partial x_{i}}\left(x_{i}^{*}, x_{j}^{*} ; k_{i}, k_{j}\right)=0
$$

Since the optimal actions $x_{i}$ and $x_{j}$ depend only $k_{i}$ and $k_{j}$, we can define a reduced-form product market profit for firm $i$ as follows:

$$
R_{i}\left(k_{i}, k_{j}\right) \equiv \Pi_{i}\left(x_{i}^{*}\left(k_{i}, k_{j}\right), x_{j}^{*}\left(k_{i}, k_{j}\right), k_{i}\right) .
$$

We shall assume that the reduced-form product market profit $R_{i}\left(k_{i}, k_{j}\right)$ is strictly increasing in the own capital holdings and strictly decreasing in the rival's capital holdings, i.e. we assume:

Assumption 1: $\frac{\partial R_{i}}{\partial k_{i}}>0$ and $\frac{\partial R_{i}}{\partial k_{j}}<0$

To keep the exposition simple we use the derivatives of reduced-form product market profits in Assumption 1, $\frac{\partial R_{i}}{\partial k_{i}}$ and $\frac{\partial R_{i}}{\partial k_{j}}$, keeping in mind that these summarize the total effects on the product market profits. These total effects are spelled out in detail in the Appendix A.1.

As also shown in Appendix A.1, Assumption 1 holds in the Linear-Quadratic Cournot model used in section 4. But assumption 1 is also compatible with other oligopoly models. For example, Farrell and Shapiro (1996) show that under Cournot competition and under general assumptions on demand and costs, that an increase in capital for a firm (i) increases 
this firm's profit, while (ii) decreasing the profits of its competitors. Moreover, using a quantity-setting conjectural variation oligopoly model under a set of stability criteria, Dixit (1986) shows that a change, which is prima facie favorable for a firm, as is an increase in effective capital, reduces the profits of all other firms. Finally, it can be shown that Assumption 1 extends to a linear Bertrand model with differentiated goods.

\subsection{Stage 3: Optimal investment by the non-acquirer}

The non-acquirer makes its investment decision, $k_{N A}$, taking as given the investment made by the acquirer, $k_{A}$. To highlight simply the different incentives for restructuring facing the government and the acquirer, we assume without loss of generality that a non-acquiring firm faces a discrete investment decision, $k_{N A}=\bar{k}$, which is always profitable, i.e. we assume $R_{N A}\left(\bar{k}, k_{A}\right)-F>0$, where $F$ is a fixed investment cost. While simplifying the exposition, this assumption is not crucial and in the Appendix A.4 we show that continuous investments for the non-acquirer can also be included.

It is then convenient to define the total profit for the non-acquirer as the reduced product market profit net of the investment cost, and write this as a function of the acquirer's investment, $k_{A}$ :

$$
\pi_{N A}\left(k_{A}\right) \equiv R_{N A}\left(\bar{k}, k_{A}\right)-F
$$

where we can note that from Assumption $1, \pi_{N A}\left(k_{A}\right)$ is strictly decreasing in the acquirer's investment, $k_{A}$. 


\subsection{Stage 2: Optimal Restructuring (sequential investments) by the acquirer}

To describe the investment decision by the acquirer, let us again define total profit as the reduced product market profit, $R_{A}\left(k_{A}\right)$, net of the investment cost:

$$
\pi_{A}\left(k_{A}\right) \equiv R_{A}\left(k_{A}\right)-C\left(k_{A} ; k_{G}\right)
$$

where $C\left(k_{A} ; k_{G}\right)$ is the total cost of restructuring state assets, given the choice of the government, $k_{G}$. We assume that the marginal cost to be increasing and convex, i.e. $C^{\prime}\left(k_{A} ; k_{G}\right) \geq 0$ and $C^{\prime \prime}\left(k_{A} ; k_{G}\right) \geq 0$. Note that we omit the investment by the nonacquirer as an argument since $k_{N A}=\bar{k}$ is fixed by assumption. We shall also assume that $C\left(k_{A}\right)$ is sufficiently convex, so that $\pi_{A}\left(k_{A}\right)$ is strictly concave in $k_{A}$, i.e. so that $\frac{d^{2} \pi_{A}}{d k_{A}}<0$. Given the choice of government, $k_{G}$, the acquirer maximizes its total profit $\pi_{A}\left(k_{A}\right)$ in (3.4) by choosing $k_{A}$ optimally, thereby facing the following marginal investment costs:

$$
C^{\prime}\left(k_{A} ; k_{G}\right)=\left\{\begin{array}{c}
0: k_{A} \leq k_{G} \\
C^{\prime}\left(k_{A}\right): k_{A}>k_{G}
\end{array}\right.
$$

To proceed, we define the optimal choice by the acquiring firm if the government would not invest at all (i.e. $k_{G}=k_{0}$ ), as $k_{A}^{\mathcal{A}}$. Maximizing $(3.4), k_{A}^{\mathcal{A}}$ is given from:

$$
\frac{d \pi_{A}}{d k_{A}}=\frac{d R_{A}}{d k_{A}}-C^{\prime}\left(k_{A}\right)=0
$$

where $k_{A}^{\mathcal{A}}$ is illustrated in point $\mathcal{A}$ in the upper diagram in Figure 3.1. As also shown in the figure, the optimal choice of $k_{A}, k_{A}^{*}$ is then:

$$
k_{A}^{*}=\left\{\begin{array}{l}
k_{G}: k_{A}^{\mathcal{A}} \leq k_{G} \\
k_{A}^{\mathcal{A}}: k_{A}^{\mathcal{A}}>k_{G}
\end{array}\right.
$$




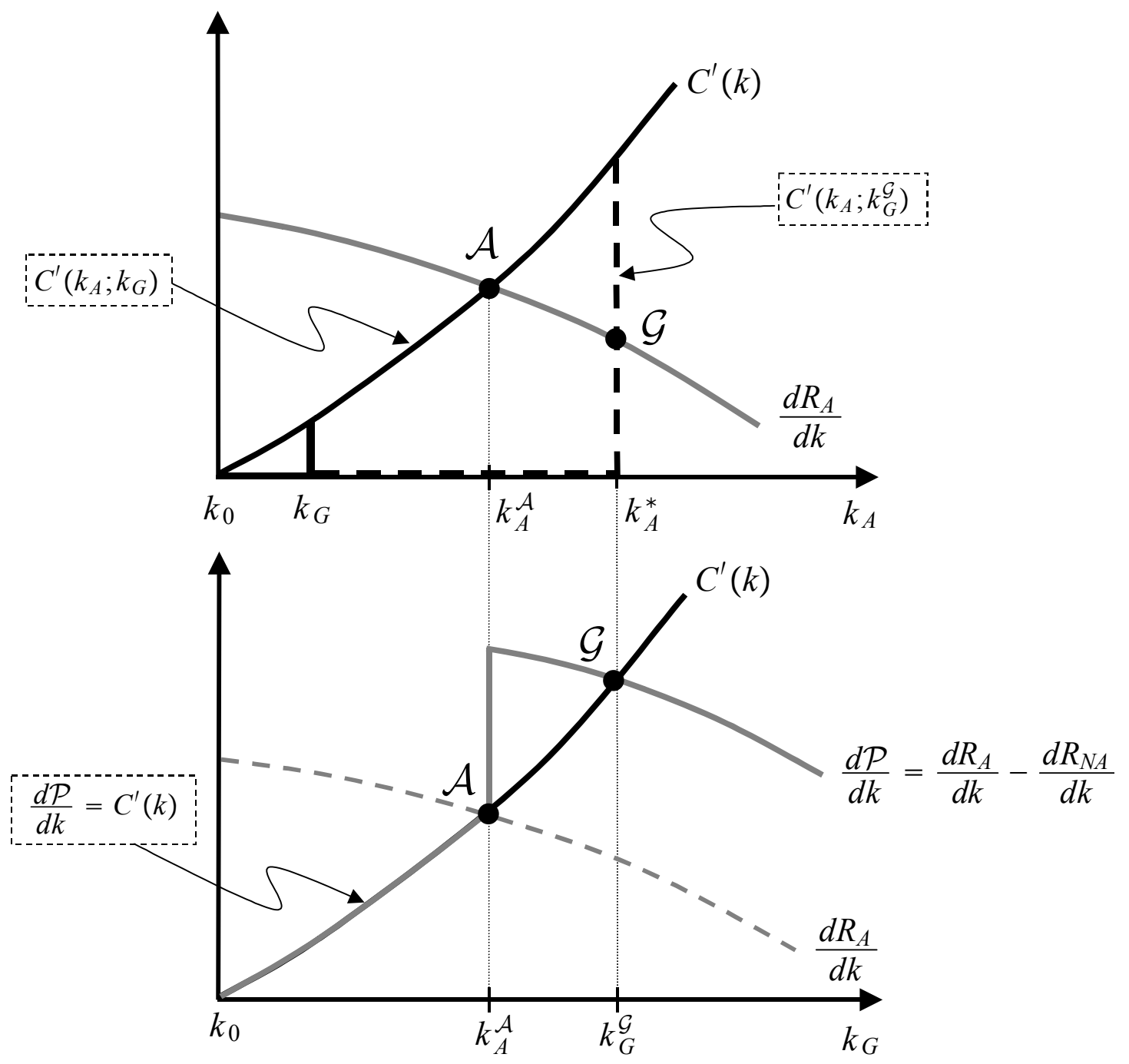

Figure 3.1: Comparison of government and private incentives to restructuring.

Hence, whenever $k_{A}^{\mathcal{A}} \leq k_{G}$, the acquiring firm refrains from restructuring and just uses the (cost-less) capacity installed by the government, $k_{A}^{*}=k_{G}$. Given that $k_{A}^{\mathcal{A}}>k_{G}$, the optimal capacity $k_{A}^{*}=k_{A}^{\mathcal{A}}$ is given from (3.6). 


\subsection{Stage 1: The privatization procedure}

The privatization auction will be solved for Nash equilibria in undominated pure strategies. $^{7}$

Let us first turn to the firms' valuations of the state assets. The valuation for firm $i$, $v_{i}$, is defined $v_{i} \equiv \pi_{A}\left(k_{A}^{*}\right)-\pi_{N A}\left(k_{A}^{*}\right)$, where $\pi_{N A}\left(k_{A}^{*}\right)$ denotes the reduced-form total profit made by firm $i$ when firm $j$ has acquired the state assets and $\pi_{A}\left(k_{A}^{*}\right)$ denotes the reducedform total profit made by firm $i$ when it has acquired the state assets itself, and where $k_{A}^{*}$ is the optimal investment by the acquirer given from (3.7). Since firms are symmetric ex-ante, it also follows that $v_{i}=v_{j}$.

In the case of two firms in the industry, the analysis is straightforward as shown by the following lemma:

Lemma 1. Let firm $i$ be the firm with the highest valuation. The state assets are then acquired by firm $i$, at a price equal to firm $j$ 's valuation of obtaining the state assets instead of firm $i, v_{j}$.

Proof. See the Appendix.

We now proceed to the government's restructuring decision.

\subsection{Stage 0: Optimal Restructuring by the government}

In period 0 , the government internalizes the dependency of the acquirer's capacity investment, $k_{A}^{*}$, on its own investment, $k_{G}$. To focus on strategic product market effects, we

\footnotetext{
${ }^{7}$ There is assumed to be a smallest monetary unit, denoted $\varepsilon$. We assume ties to be randomly broken, and all equalities in valuations to be ruled out. The smallest amount $\varepsilon$ is chosen such that all inequalities are preserved if $\varepsilon$ is added or subtracted.
} 
assume that the government maximizes the net acquisition price, i.e., the acquisition price net the restructuring cost, which from Lemma 1 can be written, $\mathcal{P}=v_{j}-C\left(k_{G}\right)$, where $v_{j}$ is the non-acquirer's valuation. We then assume that the government and the acquirer face the same cost function when restructuring, $C(k)$. The implications of relaxing these assumptions are discussed in the concluding section.

In order to describe the governments restructuring problem, it is again convenient to write the acquisition price as a function of reduced-form profits net of investment costs. From (3.7), it follows that the reduced form product market profits $R_{A}\left(k_{A}\right)$ and $R_{N A}\left(k_{A}\right)$, can be written as a direct functions of $k_{G}$. Using the symmetry among the bidding firms, it then follows from Lemma 1 and (3.7) that the net acquisition price, $\mathcal{P}$, can be written: $\pi_{A}\left(k_{A}^{\mathcal{A}}-k_{G}\right)$

$$
\mathcal{P}\left(k_{G}\right)= \begin{cases}\pi_{A}\left(k_{A}^{\mathcal{A}}-k_{G}\right)-\pi_{N A}\left(k_{A}^{\mathcal{A}}\right)-C\left(k_{G}\right), & k_{G}<k_{A}^{\mathcal{A}} \\ R_{A}\left(k_{G}\right)-\left[R_{N A}\left(k_{G}\right)-F\right]-C\left(k_{G}\right), & k_{G}>k_{A}^{\mathcal{A}}\end{cases}
$$

where $\pi_{A}\left(k_{A}^{\mathcal{A}}-k_{G}\right)=R_{A}\left(k_{A}^{\mathcal{A}}\right)-C\left(k_{A}^{\mathcal{A}}-k_{G}\right)$ and $\pi_{N A}\left(k_{A}^{\mathcal{A}}\right)=R_{N A}\left(k_{A}^{\mathcal{A}}\right)-F$. Thus, the firstline in (3.8) shows the acquisition price when the acquirer invests (restructures) $k_{A}^{\mathcal{A}}-k_{G}>0$ sequentially upon the acquisition, whereas the second line in (3.8) indicates the acquisition price when the acquirer uses all the government's restructured capital (without sequential investment), $k_{A}^{\mathcal{A}}=k_{G}$.

The government's maximization problem is illustrated in the lower diagram in Figure 3.1. Foreseeing the acquirer's optimal restructuring, $k_{A}^{*}$, the marginal benefit of restructuring for $k_{G} \leq k_{A}^{\mathcal{A}}$ is simply $C^{\prime}(k)$. The government then only affects the cost of achieving the acquirer's optimal restructuring, $k_{A}^{\mathcal{A}}$, but these cost savings for the acquirer directly 
increases the acquisition price, leaving the net acquisition price $\mathcal{P}$ unchanged. This follows directly from (3.7) where the level $k_{A}$ is not changed.

However, if we suppose that the government reflects on a capacity choice $k_{G}>k_{A}^{\mathcal{A}}$, making use of (3.3), the first-order condition from maximizing the acquisition price $\mathcal{P}\left(k_{G}\right)$ in (3.8) net of the investment cost $C\left(k_{G}\right)$, is:

$$
\frac{d \mathcal{P}}{d k_{G}}=\frac{d R_{A}}{d k_{G}}-\frac{d R_{N A}}{d k_{G}}-C^{\prime}\left(k_{G}\right)=0
$$

where we shall assume that $C(k)$ is sufficiently convex so that $\mathcal{P}$ is strictly concave in $k_{G}$.

The optimal $k_{G}$ is indicated as $k_{G}^{\mathcal{G}}$ in the lower diagram in Figure 3.1. Comparing expressions (3.6) and (3.9), we see that the government has stronger incentives to invest in capacity than the acquiring firm. This is because the government achieves a higher acquisition price by not only taking into account the increase in profits for the acquirer, but also by exploiting the negative externalities on the non-acquirer, captured by the last term $\frac{d R_{N A}}{d k_{G}}$ which is negative from Assumption 1. This is also illustrated in Figure 3.1, where we may note that it is indeed also optimal for the acquiring firm to fully use the government investment.

Thus we have the following result:

Proposition 1. The government has a stronger incentive to restructure the state assets than the acquiring firm, since it internalizes the negative effect of restructuring on the non-acquiring firm's profit through the sale price.

In the introduction, we posed the question of why a government would restructure state assets for sale instead of leaving it to a future buyer to decide. The private buyer should 
be able to achieve restructuring at the same cost and more in line with her specific needs. However, Proposition 1 illustrates that in an oligopoly, restructuring will have strategic product market effects which increase sales revenue by taking advantage of market rivalry among firms (by improving the competitive position of the acquiring firm while worsening the competitive position of the non-acquiring firm). This may provide the government with incentives to restructure prior to privatization.

Finally, we have assumed that the timing of investments/restructuring is: (1) the government, (2) the acquirer, and (3) the non-acquirer. If the timing of the investment was instead, (1) the government, and (2) the acquirer and the non-acquirer investing simultaneously, it can be shown that the incentive for the government to restructure relative to the acquirer would increase further. The reason being that the government then has a possibility of committing to large investment, a commitment not available to the private buyer. If all investment take place simultaneously by all players, i.e. (i) the government, the acquirer and the non-acquirer, this first-mover advantage for the government is lost. However, because the government internalizes the externalities on rival firms via the sales price, it still has a stronger incentive to restructure than the acquirer.

\section{Why speed may be important in privatizations}

While the result in the previous section provides an argument why governments use restructuring programs, the importance of selling the domestic assets quickly has also been highlighted. Lopez-de-Silanes (1997) has shown that a slow selling in the Mexican privatization program lead to a substantially lower sales price. A slow sale of the assets may lead 
to lower productivity due to, for instance, managerial distraction, misconduct and lost investment opportunities. ${ }^{8}$ In a situation without oligopolistic interaction the acquisition price would decrease with the amount of waste. However, in an oligopoly a slow sale of the state assets will have strategic investment and product market effects that affect the sales price in an involved way. In this section we will study these strategic effects in more detail.

To this end we apply a Linear-Quadratic model which allows to us derive analytical unique solutions for the optimal behavior by firms at all stages of the game. For completeness, we relax the assumption of fixed investments by the non-acquiring firm. This type of framework, typically modelling an investment game followed by a stage with oligopoly interaction, has been applied in for example, Neary (2002), Neary and Leahy (1997) and d'Aspremont and Jaquemin (1988). A central difference between these papers and our study, is that our application examines the effects of adding an acquisition game to the oligopoly- and investment interaction.

In order to highlight the strategic investment and product market effects of a slow sale, we assume that the government fails to restructure when trying, i.e. we assume that the state assets remain at $k_{0}$ after restructuring. The results in this section would also hold if this assumption was relaxed, but the analysis would then be much more tedious.

In Section 4.1 we investigate the case where a slow sale implies that the buyer loses its possibility of committing to sequential investments.

In Section 4.2 we allow different types of capital to have different effects on firms'

\footnotetext{
${ }^{8}$ On the other hand, incentives may not deteriorate if career concerns make managers of SOEs eager to establish a good reputation in the labor market. See Roland and Sekkat (2000).
} 
production possibilities. This implies that we can identify other situations where a slow sale of the state assets might cause a substantial fall in the acquisition price as a result of strategic effects.

\subsection{Delayed privatization: first-mover advantage in investments}

In this section, we assume that an acquisition provides the acquiring firm with a first-mover advantage in the investment game, allowing this firm to act first as a "Stackelberg-leader". However, this position is only attainable given that privatization takes place with speed (henceforth, indicated $S$ ). In contrast, a delay in the privatization (henceforth, indicated $D)$ causes a loss of the the first-mover advantage for the acquirer, which implies that the investment game takes place in simultaneous moves (stage two and three of the game taking place simultaneously).

\subsubsection{The product market}

The game is solved by backward induction. We model the oligopoly interaction in the last stage as Cournot competition in homogeneous goods. Let the inverse demand in the product market be given by (4.1):

$$
P=a-b\left(q_{i}+q_{j}\right)
$$

where $q_{i}$ and $q_{j}$ are the quantities produced by firm $i$ and firm $j, a>0$ is a demand parameter, $b$ may be interpreted as the (inverse) size of the market. The product market

profit for firm $i, \Pi_{i}\left(q_{i}, q_{j}, k_{i}, k_{j}\right)$, can be written:

$$
\Pi_{i}=\left(P-c_{i}\right) q_{i}
$$


where we assume that the firm's marginal cost, $c_{i}$, is decreasing in its own capital ownership:

$$
c_{i}=c-k_{i}
$$

Making use of (4.1) in the first-order condition (3.1), leads to the following Nash-quantities:

$$
q_{i}^{*}\left(k_{i}, k_{j}\right)=\frac{\Lambda+2 k_{i}-k_{j}}{3 b}
$$

where $\Lambda=a-c>0$.

From (4.1), the first-order condition (3.1) can be re-written $P-c_{i}=b q_{i}$. Hence, the reduced-form product market profits defined in $(3.2), R_{i}\left(k_{i}, k_{j}\right)$, take the form:

$$
R_{i}\left(k_{i}, k_{j}\right)=b\left(\frac{\Lambda+2 k_{i}-k_{j}}{3 b}\right)^{2}
$$

\subsubsection{Investments}

Let us start with the case where the privatized assets are sold slowly, which as stated above implies that the investment game takes place in simultaneous moves.

The total profit for firm $i$ can then be written:

$$
\pi_{i}\left(k_{i}, k_{j}\right) \equiv R_{i}\left(k_{i}, k_{j}\right)-C_{i}\left(k_{i}\right)
$$

where we shall assume a quadratic cost of investments into capital:

$$
C_{i}\left(k_{i}\right)=\frac{\mu k_{i}^{2}}{2}
$$

For simplicity, we assume that all firms share the same investment technology in terms of the cost-parameter $\mu$. Firm $i$ then invests in capital $k_{i}$, taking as given the capital 
investments of its opponent, $k_{j}$. Formally, optimal investment involves setting:

$$
\frac{\partial \pi_{i}}{\partial k_{i}}=\frac{\partial R_{i}}{\partial k_{i}}-C^{\prime}\left(k_{i}\right)=0
$$

Using (4.5) and (4.7) in (4.8), it is straightforward to derive the reaction function of the non-acquirer as:

$$
k_{N A}\left(k_{A}\right)=\frac{\Lambda-k_{A}}{\frac{9}{4} \mu b-2}
$$

The reaction function of the non-acquirer is illustrated in Figure 4.1 where it is inverted and written as $\mathcal{R}_{N A}\left(k_{A}\right)=\Lambda-\left(\frac{9}{4} b \mu-2\right) k_{N A}$, where $\frac{9}{4} \mu b-2>0$ is assumed to ensure a downward-sloping reaction function. Noting that the reaction function of the acquirer is then $\mathcal{R}_{A}\left(k_{N A}\right)=\frac{\Lambda-k_{N A}}{\left(\frac{9}{4} \mu b-2\right)}$, it is straightforward to derive the Nash equilibrium investment levels:

$$
\begin{aligned}
k_{A}^{\mathcal{N}^{D}} & =4 \frac{\Lambda(3 b \mu-4)}{(9 b \mu-4)(3 b \mu-4)} \\
k_{N A}^{\mathcal{N}^{D}} & =4 \frac{\Lambda(3 b \mu-4)}{(9 b \mu-4)(3 b \mu-4)}
\end{aligned}
$$

where it can be shown that $(3 b \mu-4)>0$ ensures uniqueness and stability and where $\mathcal{N}^{D}$ indicates simultaneous Nash-solution under delayed privatization.

Let us now turn to the case where the privatized firm is sold fast. The acquirer will then have a first mover advantage. The acquirer will choose its investment internalizing the non-acquirer's behavior through the reaction function (4.9). We can then rewrite the total profit of the acquirer in (3.4) as:

$$
\pi_{A}\left(k_{A}\right) \equiv R_{N A}\left(k_{A}, k_{N A}\left(k_{A}\right)\right)-C_{A}\left(k_{A}\right)
$$




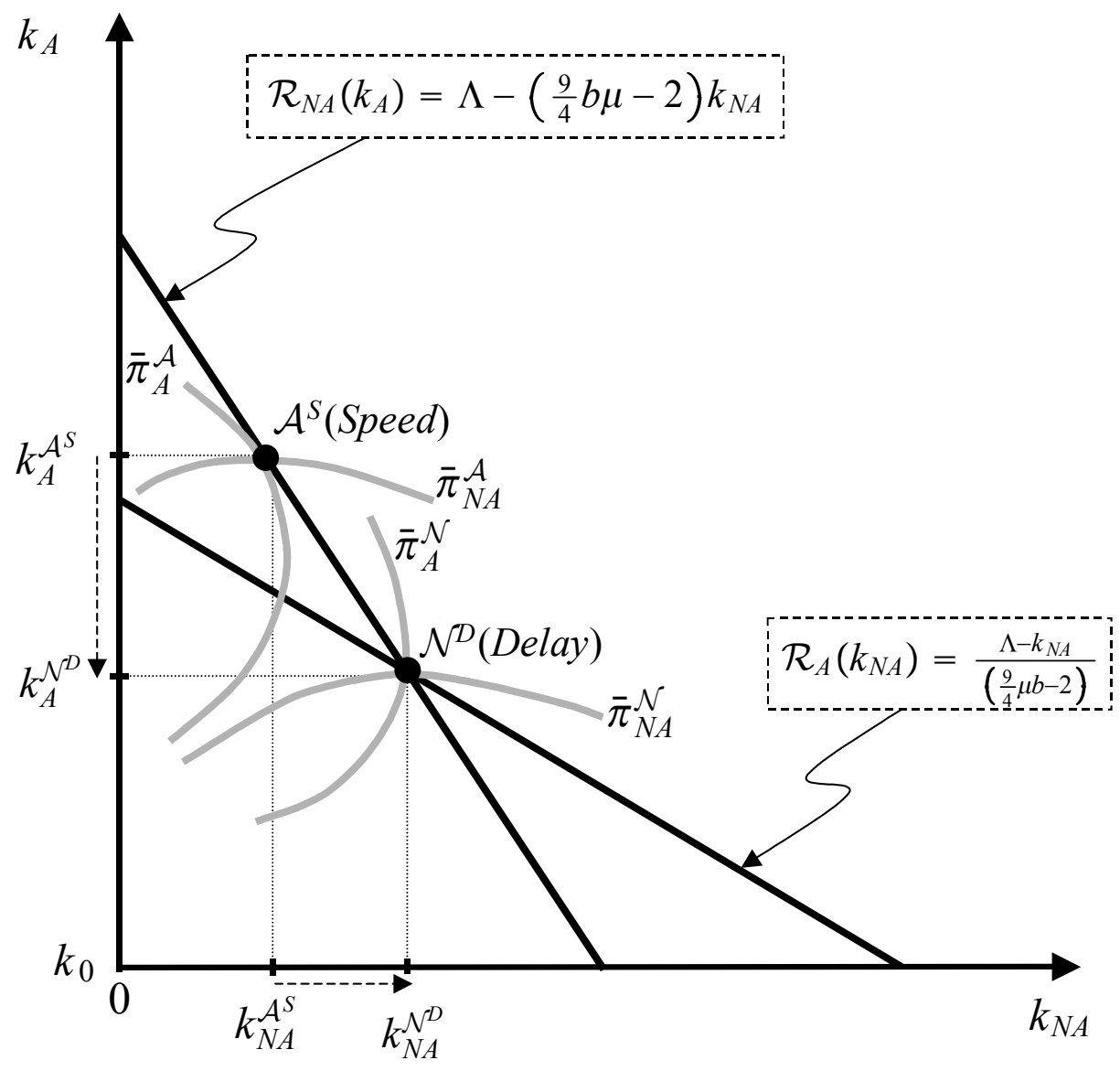

Figure 4.1: The investment game under speedy $(S)$ and delayed privation $(D)$ with homogenous capital. 
Using the reaction function (4.9) and the reduced profit product market profit (4.5), the first-order condition is:

$$
\frac{d \pi_{A}}{d k_{A}}=\frac{\partial R_{A}}{\partial k_{A}}+\frac{\partial R_{A}}{\partial k_{N A}} \frac{d k_{N A}}{d k_{A}}-C^{\prime}\left(k_{A}\right)=0
$$

Using the investment cost function (4.7), the reaction function (4.9) and the reduced profit product market profit (4.5), it can be shown that the optimal investment by the acquirer, denoted $k_{A}^{\mathcal{A}}$, and the subsequent investment by non-acquirer, denoted $k_{N A}^{\mathcal{A}}$, are:

$$
\begin{aligned}
k_{A}^{\mathcal{A}^{S}} & =4 \frac{\Lambda(3 b \mu-2)(3 b \mu-4)}{160 b \mu-216 b^{2} \mu^{2}+81 b^{3} \mu^{3}-32} \\
k_{N A}^{\mathcal{A}^{S}} & =4 \frac{\Lambda\left(9 b^{2} \mu^{2}-20 b \mu+8\right)}{160 b \mu-216 b^{2} \mu^{2}+81 b^{3} \mu^{3}-32}
\end{aligned}
$$

where $160 b \mu-216 b^{2} \mu^{2}+81 b^{3} \mu^{3}-32>0$ holds from the second order condition $\frac{d^{2} \pi_{A}}{d k_{A}^{2}}<0$ and $9 b^{2} \mu^{2}-20 b \mu+8>0$ is assumed to have positive investments by the non-acquirer, and where $\mathcal{A}^{S}$ indicates the "Stackelberg-solution" under speedy privatization.

Comparing the outcomes under delayed $(D)$ and speedy $(S)$ privatization, we can state the following Lemma.

Lemma 2. In the Linear-Quadratic model, $k_{A}^{\mathcal{A}^{S}}>k_{A}^{\mathcal{N}^{D}}$ and $k_{N A}^{\mathcal{A}^{S}}<k_{N A}^{\mathcal{N}^{D}}$.

Proof. See, the Appendix.

Lemma 2 is also illustrated in Figure 4.1. Note that under delayed privatization $\left(\mathcal{N}^{D}\right)$, the first-mover advantage for the acquirer is lost and the acquirer cannot commit to a large investment and hence reduces its sequential investments as compared to the case of speedy privatization $\left(\mathcal{A}^{S}\right)$. In contrast, the corresponding change for the non-acquirer involves an increase in investments. 


\subsubsection{Effects on the acquisition price}

Turning to the effect of the acquisition price of a slow sale. To illustrate the effects of a slow sale of the state assets, first define $\pi_{i}^{l} \equiv \pi_{i}^{l}\left(k_{i}^{l}, k_{j}^{l}\right)$ as the reduced-form total profit for firm $i$ under slow or speedy sale, respectively, i.e. $l=\left(\mathcal{N}^{D}, \mathcal{A}^{S}\right)$. The corresponding iso-profit curves are denoted $\bar{\pi}_{i}^{l}$ and are also shown in Figure 4.1. For instance, $\bar{\pi}_{A}^{\mathcal{A}}$ is then the acquirer's reduced-form total profit when privatization takes place with speed. Then, define $\mathcal{P}^{\mathcal{D}-\mathcal{S}}=\mathcal{P}^{\mathcal{N}^{D}}-\mathcal{P}^{\mathcal{A}^{S}}$ as the difference in acquisition price under delayed $(D)$ and speedy $(S)$ privatization, that is:

$$
\begin{aligned}
\mathcal{P}^{\mathcal{D}-\mathcal{S}} & =\left[\pi_{A}^{\mathcal{N}^{D}}-\pi_{N A}^{\mathcal{N}^{D}}\right]-\left[\pi_{A}^{\mathcal{A}^{S}}-\pi_{N A}^{\mathcal{A}^{S}}\right] \\
& =[\underbrace{\pi_{A}^{\mathcal{N}^{D}}-\pi_{A}^{\mathcal{A}^{S}}}_{(-)}]-[\underbrace{\pi_{N A}^{\mathcal{N}^{D}}-\pi_{N A}^{\mathcal{A}^{S}}}_{(+)}]<0
\end{aligned}
$$

As again illustrated in Figure 4.1, firms' valuation of the state assets are reduced from a delay of the privatization. Formally, expression (4.16) then shows that the acquisition price is reduced for two reasons: First, the first-mover advantage is lost for the acquirer, which from Lemma 2 and (4.5) reduces the acquirer's profit. Second, the loss of first-mover advantage of the acquirer also improves the competitive position of the non-acquirer, which from Lemma 2 and (4.5), leads to an increase in this firm's profit.

Therefore, a slow sale then reduces firms willingness to pay, since the delay reduces the acquirer's profit, while the profit of the non-acquiring firms increases. In sum:

Proposition 2. A slow sale of state assets which removes the acquirer's first-mover advantage in the investment game, reduces the sales price for two reasons: (i) it reduces the acquiring firm's product market profit, and (ii) it increases the non-acquiring firm's 
product market profit.

\subsection{Delayed privatization: depreciation of irreplaceable assets and other first- mover advantages}

In the analysis so far we have treated the state assets, restructured assets and new assets as perfect substitutes. However, these different types of capital might have significantly different effects on firms' production possibilities. In some situations, the state assets may be unique and irreplaceable. For example unique land or natural resources might be destroyed by misconduct during a slow sale. Another situation is when early entry provide the acquiring firm with a competitive advantage in the ensuing product market competition. For example, an early entry might give the acquirer an opportunity to create consumer loyalty before rival firms enter the market.

To model heterogenous capital of this kind, let the marginal cost for firm $i$ be:

$$
c_{i}=\bar{c}_{i}-k_{i}, \quad \text { where: } \quad \bar{c}_{N A}=c, \quad \bar{c}_{A}=c-\gamma^{l} k_{0}
$$

In (4.17) $k_{i} \neq k_{0}$ again denotes invested (new) capital in stage two. Asymmetries between firms are captured by the intercept term, $\bar{c}_{i}$, which measures the impact on firm $i$ 's absolute efficiency level of the possession of all other assets (such as firm-specific assets or acquired state assets) prior to investment in new assets, $k_{i}$, in stage $2 .{ }^{9}$ Hence, state assets $k_{0}$ and new assets $k_{i}$ are assumed to be imperfect substitutes. $k_{0}$ may, for instance, provide knowledge of the market, thereby providing assets distinct from new investments $k_{i}$, which

\footnotetext{
${ }^{9}$ Assuming that asymmetries between firms enter through the intercept term $\bar{c}_{i}$ in the marginal cost $c_{i}=\bar{c}_{i}-k_{i}$ simplifies the calculations. Alternatively, we could assume that firms differ in their investment costs for new investments $\left(\mu_{i}\right)$. Qualitatively, this yields similar results.
} 
provide a capacity to produce. To capture the effect of delayed privatization, we introduce the efficiency parameter $\gamma^{l}$ and make the following assumption:

\section{Assumption 2: $\gamma^{S}>\gamma^{D}$}

We noted above that a slow or delayed privatization might lead to (i) unique assets being depreciated or destroyed while waiting, or that (ii) first mover advantages from an early entry (such as creating consumer loyalties) may not materialize. ${ }^{10}$ Assumption 2 captures both these features of a delay assuming that the "effective size" of the former state assets, as captured by the parameter $\gamma^{l}$, is larger when privatization take place with speed $(l=S)$ than with a delay $(l=D)$, that is, $\gamma^{S} k_{0}>\gamma^{D} k_{0}$.

Let us then turn to the investment game. To highlight the effect of delay in this context of unique state assets, we shall assume investment into new assets take place simultaneously (i.e. stage two and three of the game take place simultaneously). ${ }^{11} \mathrm{We}$ need then merely to replace firms' marginal costs in (4.3) with the marginal cost in (4.17). The reaction function of the non-acquirer then becomes:

$$
k_{N}\left(k_{A}\right)=\frac{\Lambda-\gamma^{l} k_{0}-k_{A}}{\frac{9}{4} \mu b-2}
$$

which is is illustrated in Figure 4.2 where it is inverted and written $\mathcal{R}_{A}\left(\gamma^{l} k_{0}\right)=\Lambda-\gamma^{l} k_{0}-$ $\left(\frac{9}{4} b \mu-2\right) k_{N A}$, where $\frac{9}{4} \mu b-2>0$ is again assumed to ensure a downward-sloping reaction

\footnotetext{
${ }^{10}$ Note that we model the benefits of an acquisition as a reduction of the marginal cost. Alternatively, acquired assets could affect consumers willingness to pay. If goods were differentiated, an acquisition would then affect the intercept of the a acquirer's demand function, which could capture that this firm is able to create some type of consumer loyalty before the entry of a rival firm. While involving more algebra, such an extension does not qualitatively change results.

${ }^{11}$ Assuming Stackelberg-leadership for the acquirer would not lead to any qualitative change in results.
} 
function. The reaction function of the acquirer now becomes $\mathcal{R}_{A}\left(\gamma^{l} k_{0}\right)=\frac{\Lambda+2 \gamma^{l} k_{0}-k_{N A}}{\left(\frac{9}{4} \mu b-2\right)}$.

Figure 4.2 also illustrates the effects of a delay in the privatization. Since, from Assumption 2, this leads to a less efficient ownership of the state assets, the reaction function of the acquirer shifts inwards from $\mathcal{R}_{A}\left(\gamma^{S} k_{0}\right)$ to $\mathcal{R}_{A}\left(\gamma^{D} k_{0}\right)$, whereas the reaction function of the non-acquirer shifts out from $\mathcal{R}_{N}\left(\gamma^{S} k_{0}\right)$ to $\mathcal{R}_{N}\left(\gamma^{D} k_{0}\right)$. Similar to the preceding section this occurs, because with less efficient ownership of state assets the acquirer cannot commit to a large investment and hence reduce its sequential investments as compared to the case of speedy privatization $\left(\mathcal{N}^{S}\right)$. Likewise, the corresponding change for the non-acquirer again involves an increase in investments.

It is straightforward to derive:

$$
\begin{array}{rlrl}
k_{A}^{\mathcal{N}^{l}} & =4 \frac{\Lambda(3 b \mu-4)+2 \gamma^{l} k_{0}(3 b \mu-2)}{(9 b \mu-4)(3 b \mu-4)}, & l & =\{S, D\} \\
k_{N A}^{\mathcal{N}^{l}}=4 \frac{\Lambda(3 b \mu-4)-3 \gamma^{l} k_{0} b \mu}{(9 b \mu-4)(3 b \mu-4)}, & l=\{S, D\}
\end{array}
$$

from which we can derive the following Lemma 3 by using Assumption 2:

Lemma 3. In the Linear-Quadratic model with heterogenous capital, $k_{A}^{\mathcal{N}^{S}}>k_{A}^{\mathcal{N}^{D}}$ and $k_{N A}^{\mathcal{N} S}<k_{N A}^{\mathcal{N}}$

\subsubsection{Effects on the acquisition price}

Again, define $\pi_{i}^{l}\left(k_{i}^{l}, k_{j}^{l}\right)$ as the reduced-total profit for firm $i$ under delayed or speedy sale, respectively, i.e. $l=\left(\mathcal{N}^{D}, \mathcal{N}^{S}\right)$ and let $\bar{\pi}_{i}^{l}$ be the corresponding iso-profit curve. Then, define $\mathcal{P}^{D-S}=\mathcal{P}^{\mathcal{N}^{D}}-\mathcal{P}^{\mathcal{N}^{S}}$ as the difference in acquisition price under slow and speedy 


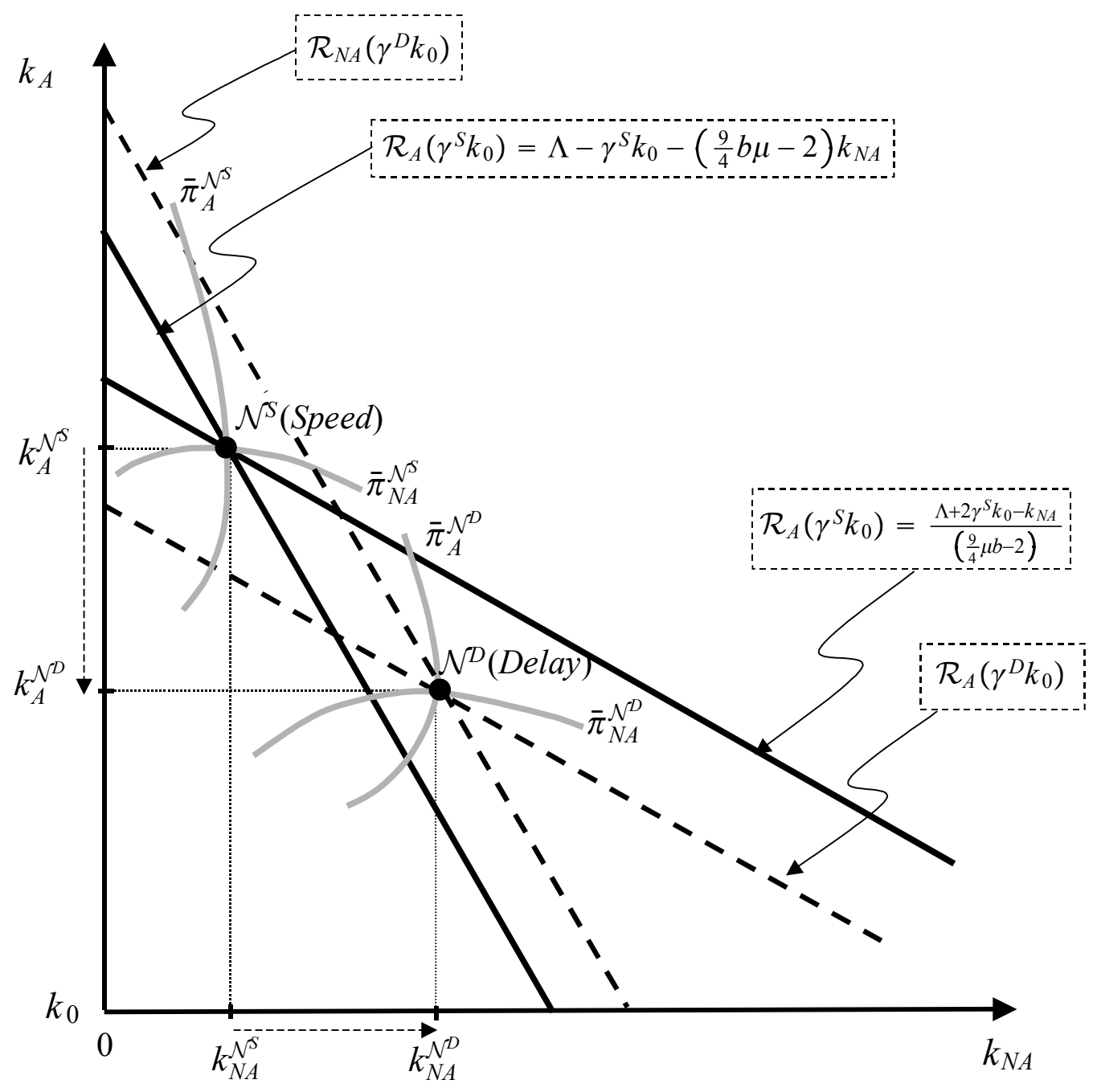

Figure 4.2: The investment game under speedy $(S)$ and delayed privation $(D)$ with heterogenous capital. 
privatization. We then have:

$$
\begin{aligned}
\mathcal{P}^{D-S} & =\left[\pi_{A}^{\mathcal{N}^{D}}-\pi_{N A}^{\mathcal{N}^{D}}\right]-\left[\pi_{A}^{\mathcal{N}^{S}}-\pi_{N A}^{\mathcal{N}^{S}}\right] \\
& =[\underbrace{\pi_{A}^{\mathcal{N}^{D}}-\pi_{A}^{\mathcal{N}^{S}}}_{(-)}]-[\underbrace{\pi_{N A}^{\mathcal{N}^{D}}-\pi_{N A}^{\mathcal{A} A}}_{(+)}]<0
\end{aligned}
$$

As shown in Figure 4.2, it again follows that firms' valuation of the state assets are again reduced from a delay of the privatization. Expression (4.16) then shows that the acquisition price is reduced for two reasons: First, as the acquirer can less efficiently use the former state assets (due to depletion or weaker complementarities) the acquirer face a less advantageous position in the investment game, which from Lemma 2 and expression (4.5) reduces the acquirer's profit. Second, this also improves the competitive position of the non-acquirer, which from Lemma 2 and (4.5), leads to an increase in this firm's profit.

Thus, a slow sale of the state assets reduces firms' willingness to pay also in a situation there state assets have an element of uniqueness. We have the following result:

Proposition 3. A slow sale of the state assets which causes depreciation of irreplaceable state assets or restricts the acquirer's possibility to exploit non-commitment first mover advantages, reduces the sales price for two reasons (i) it reduces the acquiring firm's product market profit, and (ii) it increases the non-acquiring firm's product market profit.

\section{Concluding discussion}

In this paper, we have shown that government policies used in times of investment liberalizations, such as restructuring and the timing of sales, can be explained through their strong effect on the sales price of the domestic assets. We have shown that the govern- 
ment may have a stronger incentive to restructure than the acquirer, since it internalizes externalities on rival firms via the sales price of the target firm in the host country. An acquirer restructuring only takes into account how much its own profit will increase. The government, on the other hand, takes into account how the sales price increases; it increases from an increased profit for the acquiring firm, but also from a lower profit for the non-acquiring firm, whose profits decreases as a result of its rival's restructuring.

While this provides an argument for restructuring programs, a quick sale of the domestic assets is also shown to be important. A slow sale of domestic assets might imply that the first mover advantage from entering by an acquisition of a privatized firm is reduced, since entry by rivals then becomes closer in time. The slow sale will then reduce the sales price for two reasons: (i) it reduces the acquiring firm's product market profit, and (ii) it increases the non-acquiring firm's product market profit and thus reduces the non-acquirer's willingness to pay for the assets.

To summarize, we have thus shown that government restructuring can be rationalized as a way of taking advantage of market rivalry and bidding competition in order to extract a higher acquisition price. However, if such a strategy fails or is too prolonged, the same forces can also lower the acquisition price considerably. Whether a government should opt for the potential rewards associated with restructuring, or simply sell while the state assets are in demand, is highly case-specific and will depend on the nature of the state assets, the degree of competition on the relevant market, the government's ability to restructure etc. In the Mexican privatization program it seems that restructuring was counterproductive as indicated by the following quote from Lopez-de-Silanes (1997): "A 
key lesson in privatizations is: do not do too much. Just sell".

The model used is of course restrictive in several dimensions. First, it might be questionable as to whether the government has the ability to restructure as efficiently as the buyer. In particular it seems reasonable to believe that governments abstain from restructuring in situations where their own technology is substantially inferior to the potential buyer's technology. However, the above finding might explain why a government does restructure, even though it is inferior in restructuring. Second, the bidders valuation of the state assets might differ substantially. For example, the acquirer might have firm specific assets matching particularly well the assets for sale. The acquirer might then have a stronger incentive to restructure. To see this, note that the acquisition price equals the valuation of the state assets for the firm with the second highest valuation. This firm's valuation might then not be so sensitive to restructuring, while the acquirer's profit is. However, note also that the reverse might be true. It then follows that the government's incentive to restructure relative to the acquirer increases even further.

To focus on strategic product market effects, we have assumed that the government maximizes the revenues from the sale of the state assets. In practise, it seems that revenues are in fact an important part of the objective function when privatizations takes place. However, in a welfare analysis, effects on consumers and other domestic firms might also be taken into account. The consumer effect would likely increase the government's incentive to restructure, since restructuring would likely lead to lower prices. However, business stealing from domestic rivals will then decrease the incentive for restructuring by the government, the total effect then being ambiguous. 


\section{A. Appendix:}

\section{A.1. Discussion of Assumption 1}

Denoting $\frac{d \Pi_{i}}{d k_{i}}$ and $\frac{d \Pi_{i}}{d k_{j}}$ as total derivatives, we are hence assuming that:

$$
\begin{aligned}
\frac{\partial R_{i}}{\partial k_{i}} & =\frac{d \Pi_{i}}{d k_{i}}=\frac{\partial \Pi_{i}}{\partial x_{i}} \frac{d x_{i}^{*}}{d k_{i}}+\frac{\partial \Pi_{i}}{\partial x_{j}} \frac{d x_{j}^{*}}{d k_{i}}+\frac{\partial \Pi_{i}}{\partial k_{i}}>0 \\
\frac{\partial R_{i}}{\partial k_{j}} & =\frac{d \Pi_{i}}{d k_{j}}=\frac{\partial \Pi_{i}}{\partial x_{i}} \frac{d x_{i}^{*}}{d k_{j}}<0 .
\end{aligned}
$$

Hence, the total effect for firm $i$ from obtaining more capital is positive, which from (A.1) implies that the sum of the indirect effect (which cancels through the envelope theorem, $\frac{\partial \Pi_{i}}{\partial x_{i}}=0$ ), the strategic effect (where an increase in $k_{i}$ affects firm $j: s$ optimal product market action, $\frac{d x_{j}^{*}}{d k_{i}}$, affecting profits through $\frac{\partial \Pi_{i}}{\partial x_{j}}$ ) and the direct effect (the term $\frac{\partial \Pi_{i}}{\partial k_{i}}$ ), is positive. Conversely, (A.2) implies that the strategic effect when a competitor obtains more capital (where an increase in $k_{j}$ affects firm $i: s$ optimal product market action, $\frac{d x_{j}^{*}}{d k_{i}}$, affecting profits through $\left.\frac{\partial \Pi_{i}}{\partial x_{j}}\right)$, is negative.

From section 4, we can note that using (4.1)-(4.4), $\frac{d x_{i}^{*}}{d k_{i}}>0, \frac{d x_{j}^{*}}{d k_{i}}<0, \frac{\partial \Pi_{i}}{\partial k_{i}}>0, \frac{\partial \Pi_{i}}{\partial x_{i}}>0$ and $\frac{\partial \Pi_{j}}{\partial x_{i}}<0$ holds (noting that $x_{i}^{*}=q_{i}^{*}$ ), which implies that (A.1) and (A.2) and hence Assumption 1 is fulfilled in the Linear-Quadratic Cournot model. This can also be checked by a direct calculation from (4.5).

\section{A.2. Proof of Lemma 1}

Let $v_{i}>v_{j}$ without loss of generality. First, consider the equilibrium candidate where firm $i$ acquires the state assets. Consider the equilibrium candidate $\mathbf{b}^{*}$, where $b_{i}^{*}>b_{j}^{*}$, $j \neq i$. Let owner $i$ be the owner obtaining the state assets. Note that $b_{i}^{*}>v_{i}$ is a weakly 
dominated strategy, since no owner will post a bid over its maximum valuation of obtaining the assets. If $b_{i}^{*}<v_{j}$, firm $j$ benefits from deviating to $b_{j}^{* *}=b_{i}^{*}+\varepsilon$, since it then obtains the assets and pays a price for the assets lower than its valuation of obtaining them. Last, consider candidate $b_{i}^{*}=v_{j}, b_{j}^{*}=v_{j}-\varepsilon$. Then, no owner has an incentive to deviate. Thus, this is a Nash equilibrium and the only NE where firm $i$ obtains the assets.

Let us now show that this is the only Nash equilibrium. First, consider the situation where firm $j$ obtains the assets. Consider the equilibrium candidate $\mathbf{b}^{*}$, where $b_{j}^{*}>b_{i}^{*}$, $j \neq i$. But we know that in equilibrium, $b_{j}^{*}<v_{j}$, since firm $j$ otherwise plays a weakly dominated strategy. But if $b_{j}^{*}<v_{j}$, firm $i$ benefits from deviating to $b_{i}^{* *}=b_{j}^{*}+\varepsilon$, since it then obtains the assets and pays a price which is lower than its valuation of obtaining them. Thus, firm $j$ obtaining the assets is not an equilibrium.

Second, note that the situation where neither firm $i$ nor firm $j$ obtains the assets cannot occur if there is no reservation price at the auction.

\section{A.3. Proof of Lemma 2}

Using (4.14) and (4.10), we have :

$$
k_{A}^{\mathcal{A}^{S}}-k_{A}^{\mathcal{N}^{D}}=8 \frac{\Lambda(3 b \mu-4)(9 b \mu-8) b \mu}{\left(160 b \mu-216 b^{2} \mu^{2}+81 b^{3} \mu^{3}-32\right)(3 b \mu-4)(9 b \mu-4)}>0
$$

It then follows from the reaction function (4.9) that $k_{N A}^{\mathcal{A}^{S}}<k_{N A}^{\mathcal{N}^{D}}$.

\section{A.4. Government restructuring in the linear Cournot model}

Here, we solve for the government restructuring in linear Cournot model, showing that results derived in section 3 can be derived when the non-acquirer faces a continuous in- 
vestment decision.

Assume (i) that the government faces identical investment costs as the firms, (ii) that the timing is the one in Figure 2.1, where the acquirer has a first-mover advantage and (iii) that capital is homogenous as in section 4.1. It is straightforward to also extend results to the analysis in section 4.2 with heterogenous capital. Let us, in contrast to the latter sections, also assume (iv) that the government is able to restructure. The government maximizes the acquisition price, $\mathcal{P}=v_{i}$. To derive the government's optimal restructuring, $k_{G}^{\mathcal{G}}$, assume (v) that this level of investment is larger than the optimal investment by the acquirer, $k_{G}^{\mathcal{A}^{S}}$ defined in (4.14). From (3.7), we then know that the acquiring firm will then optimally use $k_{G}^{\mathcal{G}}, k_{A}^{*}=k_{G}^{\mathcal{G}}$. Making use of the reduced-profit functions $R_{i}\left(k_{i}, k_{j}\right)$ from $(4.5)$ and the investment cost function (4.7) in the first-order condition (3.9), we can derive:

$$
\begin{aligned}
k_{A}^{\mathcal{G}} & =2 \frac{\Lambda\left(27 b^{2} \mu^{2}-44 b \mu+16\right)}{(3 b \mu-2)(9 b \mu-4)(3 b \mu-4)} \\
k_{N A}^{\mathcal{G}} & =4 \frac{\Lambda\left(9 b^{2} \mu^{2}-20 b \mu+8\right)}{(3 b \mu-4)(9 b \mu-4)(3 b \mu-2)}
\end{aligned}
$$

Using (A.4) and (4.14), we have:

$$
k_{A}^{\mathcal{G}}-k_{A}^{\mathcal{A}^{S}}=2 b \mu \frac{\Lambda\left(9 b^{2} \mu^{2}-20 b \mu+8\right)}{(3 b \mu-2)(3 b \mu-4)(9 b \mu-4)\left(160 b \mu-216 b^{2} \mu^{2}+81 b^{3} \mu^{3}-32\right)}>0
$$

where $(3 b \mu-2)(3 b \mu-4)(9 b \mu-4)>0$ by the second order condition for the government's maximization problem $(3.9), \frac{d^{2} \mathcal{P}}{d k_{G}^{2}}=-\frac{(3 b \mu-2)(3 b \mu-4)(9 b \mu-4)}{(9 b \mu-8) b}<0$, where $160 b \mu-216 b^{2} \mu^{2}+$ $81 b^{3} \mu^{3}-32>0$ by the second order condition for the acquirer's maximization problem (4.13), $\frac{d^{2} \pi_{A}}{d k_{G}^{2}}=-\frac{160 b \mu-216 b^{2} \mu^{2}+81 b^{3} \mu^{3}-32}{(9 b \mu-8)^{2} b}$, and where $9 b^{2} \mu^{2}-20 b \mu+8>0$ is required for $k_{N A}^{\mathcal{A}^{S}}>$ 0 in (4.15). Note that from (A.6) our above assumption (v) is fulfilled and the government's optimal restructuring exceeds the acquirer's optimal restructuring (investment). It is then 
indeed optimal for the acquirer to use $k_{A}^{\mathcal{G}}$ in (A.4), i.e. from (3.7), we have, $k_{A}^{*}=k_{G}^{\mathcal{G}}$. 


\section{References}

[1] Bennett, J. and Maw, J., 2000, "Privatization and Market Structure in a Transition Economy", Journal of Public Economics, 77, 357-382.

[2] d'Aspremont, C. and A. Jacquemin, 1988, "Cooperative and noncooperative R\&D in duopoly with spillovers," American Economic Review, 78(5), 1133-1137.

[3] Dixit, A. and Shapiro, C., 1986, "Entry Dynamics and Mixed Strategies." In The Economics of Strategic Planning: Essays in Honor of Joel Dean, edited by L. G. Thomas. Lexington Books.

[4] Djankov, S. and Murrell, P., 2002, "Enterprise Restructuring in Transition: A Quantitativ Survey", Journal of Economic Literature, vol. XL, 739-792.

[5] Djankov, S. and Pohl, G.,1997, "Restructuring of Large Firms in the Slovak Republic," Policy Research Paper No. 1758, The World Bank, Washington, DC.

[6] Farrell, J and Shapiro, C, 1990b, "Asset Ownership and Market Structure in Oligopoly," RAND Journal of Economics, Vol. 21, 275-292.

[7] Klemperer, P., 1995, "Competition when consumers have switching costs: an overview with applications to industrial organization, macroeconomics and international trade," Review of Economics Studies, 62(4), 515-539.

[8] Lopez-de-Silanes, F., 1997, "Determinates of Privatization Prices," Quarterly Journal of Economics, Vol. CXII, 965-1025. 
[9] Megginson, W. L. and Netter, J. M., 2001, "From State to Market: A Survey of Empirical Studies on Privatizations", Journal of Economic Literature, vol. XXXIX, pp. 321-389.

[10] Leahy, D. and P. Neary, 1997, "Public policy towards R\&D in oligopolistic industries," American Economic Review, 87:4, 642-662.

[11] Neary, J. P, 2002 "Foreign competition and wage inequality", Review of International Economics, 10:4, 680-693.

[12] Roland, Gerard,1994, "On the Speed and Sequencing of Privatisation and Restructuring," Economic Journal, v104, n426 : 1158-68.

[13] Roland, Gerard; Sekkat, Khalid, 2000, "Managerial Career Concerns, Privatization and Restructuring in Transition Economies," European Economic Review, v44, n10 : $1857-72$.

[14] Schmidt, K., M. and Schnitzer, M., 1997, "Methods of Privatization: Auctions, Bargaining and Give-aways," CEPR Discussion Paper 1541.

[15] UNCTAD, World Investment Report 2000, (United Nations Conference on Trade and Development, Geneva).

[16] Vickers, J and Yarrow, G., 1991, "Economic Perspectives on Privatization", Journal of Economic Perspectives, Vol.5, No. 2, 111-132. 